\title{
Natural philanthropy: a new evolutionary framework explaining diverse experimental results and informing fundraising practice
}

\author{
Russell James $1 \mathrm{II}$
}

\begin{abstract}
Philanthropic decision-making is important both for its potential to provide insight into human behaviour and for its economic significance. In recent years, investigations of charitable-giving behaviour have expanded substantially, including explorations from a variety of disciplinary perspectives such as economics, marketing, sociology, public administration, anthropology, evolutionary biology, political science and psychology. These investigations have resulted in a wealth of experimental results with each investigation accompanied by a discussion of potential theoretical implications. Most commonly, the various theories employed are helpful with regard to the narrow result of the investigation, but are not always useful in explaining the wider universe of results. Taking a comprehensive view of charitable-giving behaviour is thus limited to either employing a wide assortment of overlapping theoretical models, selectively applying each to fit individual phenomena, or merely referencing an ad hoc assortment of potential motivations. This circumstance suggests the value of a more unified, comprehensive approach to understanding the complete range of experimental and empirical results in charitable giving. This article proposes a comprehensive framework for philanthropic decision-making using a simple evolutionary approach incorporating interrelated fitness-enhancing strategies. The framework is then used in an extensive review of experimental and other empirical results in philanthropic decisionmaking. This review supports the framework proposition that giving depends on the tangibility of a gift's impact on altruism (direct or code), reciprocity (transactional or friendship) and possessions relative to its alternatives. Five example principles of fundraising practice demonstrate the practical applicability of this proposition: advance the donor hero story (tangibility of direct or code altruism); make the charity like family (friendship reciprocity); provide compatible publicity and benefits (transactional reciprocity); minimize perceived loss (possessions); and manage decision avoidance (relative to its alternatives). Understanding philanthropic behaviour from this perspective provides explanation and guidance for a wide range of charitable-giving behaviours and fundraising practices even in areas less amenable to traditional experimental investigation, such as charitable bequests and major gifts.
\end{abstract}

\footnotetext{
${ }^{1}$ Personal Financial Planning, Texas Tech University, Lubbock, TX, USA Correspondence: (e-mail: russell.james@ttu.edu)
} 


\section{Introduction}

hilanthropic behaviour is important for both theoretical and practical reasons. Its seeming contradiction of simple self-interest holds the promise of novel insights into human motivations. Its economic importance affects charities, markets and governments. Its day-to-day practice and encouragement is the focus of a dedicated profession.

Recent expansion of experimental investigations have generated a range of interesting results, but also a wide assortment of relatively narrow theoretical explanations and motivational descriptions. This suggests the value of attempts to provide a comprehensive theoretical framework, especially one that can generate practical suggestions for working fundraisers in areas less amenable to large-scale experimental testing, such as major gifts development. The following presents a new theoretical framework, illustrates its applications to fundraising practice and reviews related empirical research.

\section{An evolutionary framework for philanthropy}

Justification. Although the wide diversity of disciplinary approaches and theories applied to philanthropic studies can have its own value, and limitations necessarily result from privileging any single perspective, developing a comprehensive framework holds the promise of a single approach applicable across many experimental and practice circumstances. Several factors recommend an evolutionary approach for such a framework. First, an evolutionary approach has the potential for universality, framing philanthropic behaviours as natural behaviours that arise across the animal kingdom, rather than culturally specific habits of a few human societies. Second, evolutionary approaches include a long tradition of explaining different forms of altruism and resource sharing (Hamilton, 1964; Trivers, 1971; Tooby and Cosmides, 1996; Gintis, 2000), but no history of applying these theories to actual fundraising practice, suggesting the potential for profitable insights.

Description. Although the term "evolutionary" may encompass a variety of concepts, here it references inclusive gene-level fitness. Genetic variations (alleles) that tend to become more common across generations through natural selection have greater fitness than those that tend to become less common. Accordingly, behaviours reducing genetic fitness will tend to disappear over time, while those promoting genetic fitness will tend to persist.

Typically, any creature can enhance its inclusive genetic fitness by behaviour that acquires resources for itself or provides resources to genetically similar others (Hamilton, 1964). Resource acquisition can take place directly, as in hunting or gathering, or indirectly, as in reciprocity (Trivers, 1971). Transactional reciprocity involves the conditional transfer of resources. Friendship reciprocity involves the, to some extent, unconditional transfer of resources (Tooby and Cosmides, 1996). Providing resources to similar others can take place through direct altruistic transfers (Hamilton, 1964), or indirectly, through support of a code of behaviour benefitting one's group (Gintis, 2000).

Particularly relevant for fundraising practice is that when opportunities for transactional reciprocity, friendship reciprocity, direct altruism or code altruism arise in a form more relevant to the natural environments in which these behaviours were originally selected-that is, in a more tangible, naturalistic, visualizable form-they will be more likely to trigger giving behaviour. These propositions result in the following general framework for charitable-giving decisions:

Giving depends upon the tangibility of a gift's impact on altruism (direct or code), reciprocity (transactional or friendship), and possessions relative to its alternatives.
This approach does not suggest any new evolutionary mechanisms. Instead, it simply aligns previously described mechanisms into a simplified framework intended for practical application to charitable giving and fundraising. A detailed explanation of each component of the framework follows separately for (1) direct altruism, (2) code altruism, (3) transactional reciprocity, (4) friendship reciprocity, (5) possessions, (6) relative to its alternatives and (7) tangibility of impact.

Direct altruism. Hamilton (1964) proposed a simple rule for direct altruistic transfers that improve inclusive genetic fitness. Transfers will be favored by selection when $r b-c>0$, where $c$ is the cost to the donor, $b$ is the benefit to the recipient and $r$ is the genetic similarity between the donor and recipient. Transfers are preferred when the recipient is relatively needy, as this indicates high recipient benefit, $b$, relative to donor cost, $c$. Greater genetic similarity, $r$, is also preferred, but, beyond presumed kinship ties, is not directly observable. However, several observable factors do correlate with genetic similarity-such as similarity in location, behaviour, personality and physical appearance-and these, in turn, predict cooperation and altruistic sharing (Rushton, 1989).

Code altruism. An individual may also benefit others through support of a code of behaviour that improves group outcomes (Gintis, 2000). Although not a direct transfer of resources from the donor to the recipient, group members can indirectly benefit from improved outcomes resulting from group adherence to a pro-social code. Code support may be expressed by costly rewarding of code followers, costly punishment of code violators, efforts to cause other group members to internalize a code (that is, follow the code in the absence of punishment or reward) and personal internalization of a code (Fehr and Gächter, 2002; Gintis, 2003; Fehr and Schmidt, 2006).

Transactional reciprocity. Transactional reciprocity is a conditional, quid pro quo, exchange. As shown in Table 1, different types of altruism can engender different types of reciprocity. Direct altruism can generate current transactional reciprocity from the recipient (for example, invitations to donor events or improving a shared good benefitting the donor) or observers (for example, tax benefits or motivating others to give towards improving a shared good benefitting the donor). Direct altruism can also signal to observers that the donor is a high-quality partner for future transactional reciprocity relationships. This may be due to the donor's attractiveness as a producer of future-shared profits (for example, the gift displays wealth or valuable skills) or as a receiver of future-shared profits (for example, the gift displays shared support of common beneficiaries whom the donor might support with future profits). Code support altruism can generate current transactional reciprocity by avoiding punishment or eliciting rewards from code-supporting observers or by motivating others to follow a code improving the donor's social environment. Code support altruism can also signal to observers that the donor is a high-quality partner for future transactional reciprocity relationships. This may be due to the donor's attractiveness as a producer of futureshared profits (for example, the code dictates desirable transactional behaviour such as fairness) or as a receiver of future-shared profits (for example, shared support of a common code that the donor might support with future profits). In addition, shared support of the same beneficiaries or code increases the value of a transactional partner as a future profit receiver because the partner is exhibiting behaviourally similarity, which is a signal for genetic similarity. 
Friendship reciprocity. Friendship reciprocity is a mutual expectation of, to some degree, unconditional aid. Although a gift may strengthen friendship bonds, it does not generate an expectation of a specific quid pro quo transactional response. Friendship reciprocity uniquely includes an element of insurance. In time of need, a friend will help unconditionally, that is, even if help is not justified by potential transactional exchange benefits. In a natural context, receiving the benefits of such mutual insurance in a crisis can be extraordinarily important to survival. Tooby and Cosmides (1996: 132) explain:

For hunter-gatherers, illness, injury, bad luck in foraging, or the inability to resist an attack by social antagonists would all have been frequent reversals of fortune with a major selective impact. The ability to attract assistance during such threatening reversals in welfare, where the absence of help might be deadly, may well have had far more significant selective consequences than the ability to cultivate social exchange relationships that promote marginal increases in returns during times when one is healthy, safe, and well fed.

The evolutionary importance of friendships in providing supporters during times of social conflict is common even in non-humans such as chimpanzees (Fraser et al., 2008), macaques (Massen, 2010) and ravens (Fraser and Bugnyar, 2010). Friendship reciprocity is valuable but also risky, requiring mutual predictions of the future behaviour of another. Tooby and Cosmides (1996: 132) continue,

Although receiving the benefits of friendship reciprocity was critical, fulfilling the obligations of this mutual insurance was costly. Thus, maintaining successful friendships by projecting oneself-and accurately ascertaining a partner-as a valuable and "true" friend rather than a "fair weather" friend in advance of a crisis was an important and difficult task central to survival probability.

Because friendship insurance is paid or collected in the future, the ideal friendship partner is an attractive future transactional partner who is willing to fulfil friendship insurance obligations. Thus, direct or code altruism that enhances attractiveness as a future transactional partner-by displaying valuable resources, similarity, or shared support of others-also enhances attractiveness as a friendship partner. But, this must be combined with the friend's willingness to help in a crisis beyond what is transactionally justified. A current or potential friend could signal general reliability in a crisis by providing heroic sacrificial aid to another or supporting a code that mandates fulfilling friendship insurance obligations. Signalling unconditional support to a specific friend could include taking transactionally unjustified actions to please the friend (for example, unconditional gifts), especially those evidencing an emotional connection (for example, gifts reflecting a deep understanding of the friend's preferences). Conversely, signalling transactional conditionality (for example, responding to a gift with a transactional payment) telegraphs the absence of friendship insurance.

Such friendship reciprocity can encompass a wide range of relationships. Tooby and Cosmides (1996: 132) explain:

The concept of "friendship" reciprocity can include relationships with a wide variety of insurance expectations from the limited unconditional assistance of a neighbor to the lifetime commitment of a mate. 
Thus, friendship reciprocity in its strongest form can become a family or family-like relationship.

Possessions. Engaging in altruism or reciprocity involves some initial cost. Any optimizing decision must weigh this initial costin the context of its impact on one's overall possessions-against any anticipated outcomes from altruism or reciprocity.

Relative to its alternatives. A potential donor may agree to make a gift, refuse to make a gift or avoid the giving decision. Avoiding the giving decision may be attractive because, like a refusal, it involves no initial cost but may have fewer negative consequences than a blatant refusal. Refusal may more clearly violate reciprocity expectations or a code of behaviour than merely avoiding or postponing the giving decision. Eliminating avoidance as a viable alternative, for example, by making a direct request requiring an immediate response, would thus increase giving participation from some potential donors, but would, for the same reason, also be actively avoided by some.

Tangibility of impact. Altruistic and reciprocity behaviours arose long before the complexities of modern financial and organizational intermediation. Thus, presenting altruistic and reciprocity opportunities in a more naturalistic, concrete, visualizable formsuch as in a story or narrative framework (Schank and Abelson, 1995) — will more likely trigger emotional helping or reciprocity responses (Dickert and Slovic, 2009). Similarly, priming potential donors (for example, by reminders, framing or defaults) to increase attention to altruism, reciprocity or possessions can increase the subjective importance of each. These tangibility changes alter subjective evaluations even when the objective results remain the same.

\section{Example fundraising practice principles}

Introduction. The following example practice suggestions illustrate how the underlying framework can generate intuitive, realworld principles for fundraising. In the following segments, each component of the formal statement is reflected in an example practice suggestion.

Giving depends upon the tangibility of a gift's impact on altruism (direct or code), reciprocity (transactional or friendship), and possessions relative to its alternatives.

\footnotetext{
"Advance the donor hero story" [tangibility of impact on direct or code altruism]. This practice suggestion makes the underlying objective (direct or code altruism) more intuitive by targeting its strongest form. Here, a "hero" is a voluntary, sacrificial protector of group members or ideals (Franks et al., 2011), who merits lasting social approval. Protecting group members is direct altruism. Protecting ideals is code altruism. Further, the action must merit lasting social approval, meaning that heroism is socially determined, whether or not it is ever publicized.

The idea of "advancing" the donor hero story allows that although a single act may not independently rise to the level of heroic, it can nonetheless move the overall life narrative in that direction. This references the concept of "social heroism", which, as compared with the heroism of perilous physical acts, is "typically less dramatic" and "unfolds over a much longer period of time" (Franks et al., 2011: 101). Accordingly, the suggestion is to "advance" rather than "create" the donor hero story, meaning that the gift should fit within the donor's existing life narrative.

In addition, the goal is to advance the donor hero "story" rather than the donor hero "calculation", reflecting the
}

importance of more tangible forms of framing. Such advancement may take place through various methods including expressions of gratitude that confirm the heroic nature of the gift, sharing heroically framed stories of others who have made similar gifts and constructing giving opportunities that allow demonstrations of sacrificial support in a crisis.

"Make the charity like family" [tangibility of impact on friendship reciprocity]. As before, this practice suggestion makes the underlying objective (friendship reciprocity) more intuitive by targeting its strongest form, here a family or family-like relationship. This also establishes an intuitive contrast with a purely conditional market-exchange relationship. Thus, charity actions emphasizing unconditional social support (providing a small gift reflecting a deep understanding of the donor's preferences, demonstrating empathy during a crisis, expressing gratitude for the relationship) will advance the goal, while those emphasizing a purely conditional transactional relationship (caring only about the donor's money) may not. In addition, the charity can become like family by encouraging social interaction and mutual support among donors, thus building a community analogous to an extended family.

"Provide compatible publicity and benefits" [tangibility of impact on transactional reciprocity]. The third suggestion emphasizes the transactional benefits accruing to the donor resulting from the gift. These benefits can come directly from the charity or, if the gift is publicized, can come from other observers. However, providing donor benefits or publicity can be counterproductive when presented in a way that is incompatible with other goals. If donor benefits or publicity reduce beneficiary impact (due to cost to the organization) or social approval (highlighting self-interest rather than purely pro-social motives), they may impede the gift's advancement of the donor hero story. Similarly, if benefits emphasize a purely conditional market/ exchange relationship with the charity, they may conflict with the promotion of a less conditional friendship/family relationship.

"Minimize perceived loss" [tangibility of impact on possessions]. The fourth suggestion emphasizes the importance of framing the initial cost of the gift to reduce the perception of negative financial impact. For example, asking for a gift in conjunction with a windfall, the sale of an appreciated asset, or an anticipated raise allows for framing as sharing a financial gain rather than experiencing a financial loss. For a wealthy donor, asking for the same gift from assets (where it constitutes a tiny share) rather than from income (where it constitutes a much larger share) may similarly reduce the relative perception of financial loss. Other examples that reduce the perception of loss might include asking for a future commitment, rather than an immediate payment, or breaking a larger gift amount into a smaller daily equivalent (for the price of a cup of coffee a day).

"Manage decision avoidance" [relative to its alternatives]. Decision avoidance can affect fundraising in two ways. Most obviously, some donors may prefer avoiding the giving decision to either making a gift or blatantly refusing a gift. This can be addressed by an effective ask that requires an affirmative decision, thus reflecting the importance of ultimately making the donation request. However, avoidance of the donation decision can also serve as a barrier to beginning any interactions with the charity. Relieving the prospect's concern about being asked for money might allow for the development of relationships with the organization or affinity for the cause that, ultimately, could increase interest in making a gift. Thus, effective management of decision 
avoidance may require both complete abstinence from donation requests and the absolute necessity of donation requests, depending on the timing and stage of the relationship with the prospective donor.

\section{Experimental and other empirical results within an evolutionary framework}

Introduction. The previous sections of the article reviewed the theoretical basis for the proposed evolutionary framework for philanthropy and provided examples of how such a framework might be expressed in fundraising practice. The following explores experimental and empirical results from the perspective of the proposed framework. The studies are grouped according to the most relevant subcomponents of the proposed framework: (1) direct altruism, (2) code altruism, (3) transactional reciprocity, (4) friendship reciprocity, (5) possessions and (6) relative to its alternatives. Results related to "tangibility of impact" are covered in each section, as it relates to each subcomponent of the framework. Each section ends with a discussion of its related fundraising practice suggestion in light of the experimental results.

Direct altruism. Some experimental results support Hamilton's (1964) concept of maximizing recipient benefit weighted by perceived similarity. Demonstrating the importance of recipient benefit, people were more willing to give when the impact of such giving on beneficiaries was greater due to greater perceived need (Bekkers and Wiepking, 2011), reduced transaction costs (Huck and Rasul, 2010) or the availability of gift matching funds (Eckel and Grossman, 2008).

Demonstrating the importance of recipient similarity, people were more willing to give help to (Segal and Hershberger, 1999; Ben-Ner and Kramer, 2011) and expect help from (BurtonChellew and Dunbar, 2015) those known to be more closely related. Just as Hamilton's (1964) formula suggests that giving decisions to any recipient are mediated by the same calculation, biological evidence suggests that giving decisions to unrelated others are mediated by the same hormones that produce family bonding (Zak et al., 2007). Thus, charitable recipients may function as a form of hyper-extended or synthetic family.

Among unrelated others, people were more willing to benefit those they perceived as being similar to them (Karylowski, 1976; Rushton, 1989). Experimental participants were more willing to share with fellow group members in a variety of contexts such as nationality (Castro, 2008), university fraternity (Epp and Wicinas, 2001), or even when experimental instructions simply described the donor and recipient as a "two-member group" (Banerjee and Chakravarty, 2014).

However, some philanthropic behaviour does not appear to follow Hamilton's (1964) simple mathematical formula. Some of these examples spring from the motivations of code altruism or reciprocity, discussed later. Other scenarios deviate from this objective formula due to the subjective impact of tangibility. For example, in the well-documented "identifiable victim effect", appeals for a specific needy person generated more emotion (Kogut and Ritov, 2005) and donations (Jenni and Loewenstein, 1997) than those describing the needs of a large group. This identifiability reduced the effort needed to concretely visualize the beneficiary (Dickert et al., 2016). The increased mental imagery increased sympathy for the beneficiary, which, in turn, increased donations (Dickert et al., 2016).

Revealing specific details about a beneficiary makes mental images easier to form. Consequently, in a dictator game, allowing the donor to view the recipient (Bohnet and Frey, 1999), or even revealing the recipient's family name (Charness and Gneezy, 2008), increased donations. Details revealing similarity with the donor particularly increased giving. For example, people were more willing to comply with a request when the requester shared a birthday, a first name or fingerprint similarities (Burger et al., 2004). University alumni were more likely to give to a student solicitor who shared a similar first name or field of study (Bekkers, 2010).

Tangibility can be affected not only by information, but also by the way in which that information is processed. Participants instructed to listen to a beneficiary's story by taking "an objective perspective toward what is described" were less likely to donate than those told to "try to imagine how [the person] feels about what has happened and how it has affected his life" (Batson et al., 2002: 1660).

Tangibility applies not just to the recipient and the recipient's similarity, but also to the impact generated by the donor's gift. Increasing the benefit from a gift by tripling the number of recipients receiving the same benefit, by the simple mathematics of Hamilton (1964), should triple the attraction of the gift. But, increasing the number of beneficiaries also increases the total effort required to individually simulate relatable mental images or narratives. Thus, the full value of the increased benefit may not be incorporated due to a loss of tangibility. Andreoni (2007) empirically estimated this offsetting impact on donor preferences as the total benefit divided by $n^{0.68}$, where $n$ is the number of beneficiaries. The difficulty of separately visualizing many beneficiaries can be reduced by presenting them as a single, cohesive unit such as a family (people) or herd (animals). This single-unit presentation resulted in increased donations for desirable beneficiaries (Smith et al., 2013).

Even when the objective benefit remains unchanged, different framing of the connection between the donor's gift and the resulting benefit can change the tangibility of the benefit and thus change giving. For example, even when the total cost of a charitable project was fixed, donors were substantially more willing to give if their money was designated to be used for the impact share of costs (such as drilling wells), than if it was used in part for necessary overhead and administrative costs (Gneezy et al., 2014). From a rational accounting perspective, this allocation should be irrelevant. The total project cost is fixed and money is fungible. However, the allocation label is key from the perspective of visualizing the benefit resulting from the donor's personal contribution. Similarly, increased giving when allowing gifts to be restricted to specific purposes occurred even among donors who did not actually restrict their gifts (Helms et al., 2013; Eckel et al., 2017). This suggests that some part of the increased giving resulted simply from greater vividness of the benefit to the recipient-perhaps from describing specific usesrather than from an objective change in the benefit.

Imbuing the donor's, objectively fungible, contributed money with special significance in reaching a financial goal was also motivational. Thus, donors were more likely to give, and give larger amounts, towards a fixed cost project if their particular gift was made at or near the fundraising goal completion, even when, in the absence of their gift, someone else would have made the goal completion gift (Cryder et al., 2013; Klinowski et al., 2015).

In contrast to the increased motivation from contributing a piece that helped to complete a goal, if the gift's impact was instead framed relative to an insurmountably large problem, motivation fell. For example, willingness to donate to a single victim dropped when additional information was provided about the total number of people at risk (Small et al., 2007). Increasing this reference group size made respondents more likely to indicate that helping "does not seem to do much good" (Erlandsson et al., 2014: 41). Consequently, donors were more willing to help a larger proportion of a group, even if it meant helping a smaller number of recipients (Erlandsson et al., 2014). 
These results fit with the intuition generated by the practice suggestion to "advance the donor hero story". Helping a specific victim fits strongly into a heroic narrative where making a minute statistical impact on an overwhelming problem does not (even though it may be mathematically more beneficial). Giving money to drill a needed well fits into a heroic narrative more readily than giving money to pay for the utility bills of the administrative office where necessary coordination of such activities takes place, even though both are essential. Providing the final gift that completes the goal generates a more inspiring narrative even where all gifts are objectively fungible.

Were donors motivated strictly by the mathematical formula of recipient benefit, only social outcomes would matter. But, even within the exclusive context of direct altruism, the importance of tangibility suggests the sustainability of charities that are more efficient at producing tangible, motivational donor experiences than at producing efficient social outcomes.

Code altruism. Code altruism may be difficult to isolate in practice because the same gift may support a code of behaviour, benefit another in need and generate the potential for reciprocity from the recipient or others. However, experimental manipulations can eliminate the potential for direct altruism or reciprocity. In experiments with both full crowd-out (the charity receives a fixed total amount regardless of the share donated by the participant) and double-blind anonymity (no potential for social approval or reciprocity), most participants still made a donation $(57 \%$ in Crumpler and Grossman, 2008; 81\% in Hidano and Ogiso, 2012). Although such giving did not produce recipient benefit or the possibility of reciprocity, it may have expressed the donor's adherence to an internal principle or code. Anonymous giving without recipient benefit can arise outside of the lab as well. For example, a religious adherent may destroy valuable property in private, such as by a burnt offering consumed by fire or a drink offering poured on the ground as in the Iliad (Strittmatter, 1925), the Odyssey (Petropoulou, 1987) or the Pentateuch. Further, experimental participants often support behavioural codes, such as fairness or honesty, through anonymous and costly punishment of code violators (Fehr and Schmidt, 2006). The cost incurred to execute the punishment is a form of an anonymous, unreciprocated "gift" given in support of a behavioural code.

Just as tangibility is important in direct altruism, so too it can be important for code altruism. Several circumstances can increase the salience of a behavioural code. For example, Malhotra (2010) found that religious individuals were more likely to respond to appeals for charity than non-religious individuals, but only on days when they visited their place of worship. Priming participants with religious words led to increased generosity in dictator games (Shariff and Norenzayan, 2007) and, among religious donors, also led to increased costly punishment of unfair behaviour (McKay et al., 2011). Of course, a code or principle need not be religious. Simply reminding people of the concept of love by incidentally displaying the word increased charitable donations (Guéguen and Lamy, 2011).

Complying with a behavioural code becomes particularly salient when one feels the need to compensate for some other violation or deficiency in code compliance. Thus, creating an unrelated sense of guilt-for example, by writing about one's greediness or selfishness (Sachdeva et al., 2009), by making an accidental unfair split of money (Ohtsubo and Watanabe, 2013) or by failing at a task that would have benefitted another (Darlington and Macker, 1966)_increased subsequent willingness to donate. This may also explain why combining a charitable gift with the purchase of a product was more effective for sales of products that could induce a sense of guilt (for example, a hot fudge sundae or chocolate truffles), than for necessity products (for example, a box of laundry detergent or a spiral notebook) (Strahilevitz and Myers, 1998). Similarly, emphasizing a resented stereotype that a group was characterized as ungenerous led to more generous behaviour by group members (Hopkins et al., 2007). In each case, increasing attention to the need for behavioural code compliance increased subsequent giving behaviour.

From a fundraising practice perspective, the donor hero story may centre on the donor's identity as a code supporter, separate from any direct positive impact on a specific beneficiary. When this identity becomes more salient, either from reminders of one's identity or from challenges to it, then gifts that reaffirm the identity become particularly important.

Transactional reciprocity. Transactional reciprocity may come from a charity or recipient offering a direct benefit conditional on receiving a gift. However, such benefits are problematic because they blatantly reduce the size of the donor's net gift (thereby reducing beneficiary impact) while also introducing self-interested motives (thereby reducing social signalling value). Thus, in experiments, publicly providing financial benefits conditional on giving has tended to reduce donations (Ariely et al., 2009; Newman and Shen, 2012). Similarly, Eckel and Grossman (2008) found that presenting an economically identical subsidy as a rebate (that is, framed as providing a conditional benefit to the donor) made the gift less attractive than presenting it as a matching gift (that is, framed as providing a benefit to the recipient).

Unlike a conditional financial transfer from the charity, an initial, unconditional, non-monetary gift from the charity to the potential donee has tended to increase subsequent donations (Falk, 2003; Alpizar et al., 2008). Because the charity's initial gift was unconditional, the donor's subsequent contribution lacked blatant self-interest. In addition, the marginal impact of the donor's contribution could have been viewed as undiminished because the cost of the charity's gift was a sunk cost, arising independently of the individual donor's decision to contribute. Further, the charity's gift may have prompted a sense of reciprocity obligation in the potential donor. Perhaps recognizing the resulting obligation, recipients often returned (Kim, 2015) or avoided accepting (Naeem and Zaman, 2009) these unconditional gifts from charity.

Transactional reciprocity may also come from observers other than the charity or beneficiary. However, this benefit will occur only when the gift is observed and supports the observer's social norms. Accordingly, increasing the public visibility of a gift has usually increased giving behaviour (Andreoni and Petrie, 2004). This was also true of reminders that increased only the salience of observation without actually changing the objective level of observation, such as through printed eyespots (Krupka and Croson, 2016). Evidence that giving fits with others' social norms is most easily provided by examples of prior giving by others. Thus, such giving examples have generally increased the tendency to make similar gifts (Martin and Randal, 2008; Croson et al., 2009).

Transactional reciprocity from observers may be expressed by (1) an immediate transfer (or penalty) directly to the donor, (2) an indirect transfer supporting improvements to a good or environment shared with the donor or (3) a future transfer through future transactional relationships. As an example of the first form of transactional reciprocity, refusing to give when such violates a supported code can result in costly punishment (Fehr and Gächter, 2002). Donors may also believe in supernatural reciprocity, thus making anonymous giving subject to reciprocity. This belief corresponds with observations of increased giving when the need for supernatural assistance was greater (Converse et al., 2012). 
Corresponding with the second form of transactional reciprocity, a gift to support a shared good or environment may generate indirect observer reciprocity where the observer responds to the gift with one of his own. The recognition of such an effect is consistent with experiments showing that donors gave more when their gifts would be observed before, rather than after, other donors' giving decisions (Reinstein and Riener, 2012b).

Corresponding with the third form of transactional reciprocity, giving can signal the donor's quality as a potential future transactional partner (Hardy and Van Vugt, 2006). A donor may demonstrate attractiveness as a potential producer of joint profits by giving that signals wealth (Glazer and Konrad, 1996), valuable skills, or support of a code that dictates desirable transactional behaviour such as fairness (Fehr and Schmidt, 2006) or trustworthiness (Fehrler and Przepiorka, 2013). A donor may also demonstrate attractiveness as a desirable receiver of joint profits, because either the partner is similar (Hamilton, 1964) or the partner supports similar charitable beneficiaries or behavioural codes.

In experiments, philanthropic acts increased the attractiveness of potential cooperative partners. In a public goods experiment, group members rated the most generous participants as having the greatest ability to earn money for the group and to lead the group in a later task (Hardy and Van Vugt, 2006). In a separate experiment, when participants had to choose only one group member as their partner for a subsequent joint profit-making game, the most generous participants were the most frequently chosen (Hardy and Van Vugt, 2006). Similarly, Barclay and Willer (2007: 752) found that those choosing between two potential partners for a mutual benefit public goods game, "almost always chose to interact with the more generous member of the pair". Where partnership positions are limited and donations are observed, this can create competitive altruism, where players seek to be the most generous group member in order to maximize the opportunity for future transactional partnerships (Barclay and Willer, 2007).

The real-world reputational effect of philanthropy on future transactions may be most cleanly demonstrated by examples of corporate philanthropy. In theory, the competitive corporate entity maximizes only profits (Brudney and Ferrell, 2002) and thus should not have independent motives of direct or code altruism. (Having no genes to pass along, such motivations should be irrelevant.) A corporate charitable gift generating insufficient immediate transactional benefits (for example, tax benefits, sales due to coupling a product with a gift or creation of a valuable shared public good) must be justified by expected future transactional benefits through reputation enhancement. Several findings suggest that this expectation is justified. Corporate charitable giving was predictive of future revenue and customer satisfaction for consumer firms (Lev et al., 2010). Corporate philanthropy was also associated with a better reputation for characteristics of importance to customers (for example, quality of products/services), investors (for example, value as a long-term investment) and partners (for example, capacity to innovate) (Brammer and Millington, 2005).

In fundraising practice, a charitable gift may be designed to result in compatible publicity and benefits. Some personal benefits from gifting can arise simply from the charitable project itself. Thus, a gift may improve the shared social environment (for example, give because eliminating homelessness makes your community a better place to live) or a shared good (for example, give because we can all use the new church building). A charity can emphasize these communal outcomes without risk of conflicting with other benefits from donating. However, when the charity provides direct, quid pro quo financial benefits to the donor in response to a gift, these benefits may reduce both the net gift and the signal of heroism, wealth or other attractive partner characteristics for future transactional relationships.

In order to avoid this conflict, the charity can focus on providing benefits that are compatible with other positive outcomes from donating. For example, if a charity provides benefits with little or no visible marginal costs, such as an invitation to an attractive public event, then the individual donor's benefit need not be viewed as reducing the impact from the individual donor's contribution. The commonly employed raffle or charitable lottery (where the charity sells tickets to win a fixed prize) provides just such a zero marginal cost transactional benefit to the donor. Demonstrating the importance of marginal cost, charitable lottery ticket sales fell substantially when a fixed financial prize $(0 \%$ marginal cost) was replaced with a similar variable financial prize funded with $50 \%$ of each ticket purchased (50\% marginal cost) (Dale, 2004). Similarly, when a donor purchases a donated item at a charity auction, the quid pro quo transactional benefit can be viewed as costless to the charity.

Rather than providing direct transactional benefits from the charity, which might visibly reduce the net gift, a charity could instead promote transactional reciprocity among group members. This may be reflected in the common practice of developing donor communities-for example, through boards, advisory groups and donor social events-where important future transactional relationships are likely to emerge.

Reciprocity benefits from others typically require awareness of the gift, thus necessitating some level of publicity. Here too, the charity should provide this publicity in a way that is compatible with other donation goals. Thus, charities will typically publicize donor gifts on an "opt out" basis, removing the necessity for the donor to openly request apparently self-interested (anti-heroic) benefits. Where donors are hesitant to allow publicity, a fundraiser may recharacterize such publicity as a means to influence others to give, rather than as self-promotion. In this framing, the naturally hesitant donor makes a second, sacrificial gift by allowing publication of his or her generosity in order to spur additional gifts from others, thereby making publicity more compatible with donor heroism.

Friendship reciprocity. Friendship reciprocity can be relevant to philanthropic decisions when the gift demonstrates the donor's quality as a friendship partner to others, when the charity provides friendship-like benefits to donors, and when the charity facilitates friendship partnerships between its donors. As reflected in Table 1, the ideal friendship partner is an attractive future transactional partner (an attractive provider and/or receiver of resources) who is willing to fulfil friendship insurance obligations (provide future help when needed without transactional justification). Philanthropic acts can demonstrate the donor's attractiveness in both respects.

Miller (2011) likened philanthropy to a peacock's tail, as a costly display of resources. Tessman (1995) suggested that philanthropy can be a courtship display, signalling both the donor's ability and willingness to be a good parent. Given the biologically unequal costs of reproduction, women in particular would be advantaged by successfully identifying a mate willing to be more than just transactionally reciprocal. Barclay (2010), found that including small hints of philanthropic tendencies in descriptions of potential dates increased women's ratings of the described men's desirability for friendship or long-term relationships. Correspondingly, men contributed more to charity when observed by a woman rather than a man (Iredale et al., 2008).

A core challenge of friendship reciprocity is to separate true friends, who will actually deliver transactionally unjustified help in a crisis, from fair weather friends, who appear helpful in 
mundane circumstances but fail to deliver in a crisis (Tooby and Cosmides, 1996). This is problematic in safe, stable modern environments where crises that could resolve this doubt may be rare (Tooby and Cosmides, 1996). Opportunities to demonstrate altruistic behaviour in extreme or crisis scenarios would thus be particularly important signals. Kelly and Dunbar (2001) found that although women generally preferred altruists for friendships and long-term relationships, they more strongly preferred those exhibiting heroic acts of altruism. Correspondingly, reading a romantic scenario significantly increased men's subsequent willingness to engage in heroic helping (for example, running into a burning building to save a trapped victim), but only insignificantly increased willingness to engage in mundane helping (for example, working at a homeless shelter) (Griskevicius et al., 2007). Olivola and Shafir (2013) found that people were willing to donate more when informed that making the donation would require substantial pain or effort, such as running 5 miles or enduring a painful cold-pressor task. Examples of charitable fundraising efforts requiring extended fasting, plunging into cold water or walking on burning coals may reflect this preference for heroic giving (Olivola and Shafir, 2013).

Friendship reciprocity can be directly relevant for fundraisers when the charity itself provides friendship-like economic benefits. Religious giving often supports an organization providing benefits to its committed members in crisis (Iannaccone, 1998). In the United States, private foundations allow for the control of funds to remain with the donor and the donor's friends or family members, even permitting paid employment of such insiders for managerial and professional services (Hopkins, 2008). Even public charities commonly place major donors as trustees (Callen et al., 2003) with the resulting power and influence that come from controlling institutional decisions accruing to these donors. Not only may a charity respond to donations with friendship-like economic benefits, but it may also initiate the friendship relationship by providing unconditional aid to a potential future donor in time of need. Hansmann (1987) has described this as an "implicit loan" system underlying, for example, the tendency of alumni to donate to their alma maters in response to having received an education at rates below cost. Conversely, if the university violates friendship expectations, such as by refusing to admit the donor's child, donations often cease (Meer and Rosen, 2009).

Friendship reciprocity is also relevant to philanthropy when charities serve as a facilitator of important friendship relationships. The potential crisis faced by a wealthy donor is less likely to be one of destitution requiring direct economic transfers from the charity, than one of needing powerful and supportive friends during a conflict. Such friends could come from employees, partners or beneficiaries of the supported charity, or from other wealthy benefactors. Displaying both resources and shared values by supporting a shared cause helps to make the donor particularly attractive as a prospective friendship reciprocity partner for other wealthy benefactors.

Thus, the charity can serve a critical role as both powerful "friend" and facilitator of friendships with powerful others. The wealthiest charities supported by the wealthiest benefactors would be able to offer the highest level of such benefits. Correspondingly, universities that hold large endowments or charitable trusts or foundations that are large endowments are the typical recipients of major gifts. In both the United Kingdom and the United States, approximately two-thirds of all donations over $£ 1$ million (or \$1 million) go to higher education or charitable trusts or foundations (Coutts and Co, 2015). Similarly, in the United States half of charitable bequests over $\$ 20$ million go to private foundations (Eller, 2001). While some decry the reality that, for example, in higher education the largest donations go to the wealthiest universities (Nolan, 2016), these universities and their fellow benefactors also provide the most attractive and wealthiest potential friendship relationships.

The related practice principle suggests that fundraisers should strive to "make the charity like family". The role of the charity as friend and friend facilitator may be difficult to capture experimentally, but may be particularly critical for major gifts development. Practitioner advice suggests an initial period of donor cultivation of 1.5-3 years before making a major donor fundraising request (CASE, 2013). This is a period of time and effort more in line with developing friendship relationships rather than simple transactional relationships. Such an investment of time is also well outside the practical bounds of most experimental manipulations.

There is also a striking parallel between practices in major gifts fundraising and predictions of friendship reciprocity evolutionary theory. Tooby and Cosmides (1996) suggest that the evolutionarily optimal selection of friends depends on (1) number of friendship slots already filled, (2) who emits positive externalities, (3) who is good at reading your mind, (4) who considers you irreplaceable and (5) who wants the same things you want. Major donor development practice advice appears to parallel these five evolutionary optimization issues. Such advice emphasizes the importance of (1) the donor's other charitable relationships, (2) providing access to valuable relationships or benefits, (3) understanding the donor's values, tastes and preferences, (4) establishing the donor's unique value and role within the organization and (5) demonstrating that both the organization and the specific giving opportunity reflect the donor's values (Lindahl, 2009).

The practice suggestion to "make the charity like family", incorporates several relevant concepts into an intuitive, aspirational goal. For example, where a pre-existing social relationship permits it, paying a social visit to a major donor in the hospital accords with the evolutionary concept of exhibiting solidarity during a time of need as a marker of friendship insurance reliability. However, such a thought process is unnecessary if the fundraiser simply considers, "What would a good family member do?" Providing an unconditional gift evidencing a deep understanding and concern for the donor's preferences is a classic demonstration of friendship reciprocity signalling. Again, the same behaviour results from simply considering, "What would a good family member do?" A fundraiser considering the relevance of making personal visits to major donors can be guided by the same simple question. The realworld importance of this practice principle also corresponds with findings that major gifts fundraisers tend to excel at friendshiprelated skills such as emotional intelligence or memory for personal details (Pudelek, 2014).

The recommendation to "make the charity like family", also cautions against framing donor interactions using formal market exchange language and mechanisms. These may be as antithetical to family-like relations as attempting to pay one's grandmother the fair market value cash equivalent of a special holiday meal or leaving a tip for a spouse. In a technical sense, such marketexchange behaviour telegraphs the absence of friendship insurance. The suggested practice principle helps to intuitively contrast such purely conditional market-exchange behaviours from unconditional family or friendship expectations.

Possessions. In any optimizing decision, the initial cost of the gift must be justified by offsetting gain from reciprocity or advancement of altruism goals. As before, it is not only the objective economic reality of the cost that matters, but also the tangibility of the cost. Emphasizing the importance of what is given up in a gift, that is, the initial financial cost, would thus reduce interest in 
donating. In experiments, intentionally focusing participants on money reduced their willingness to help others (Vohs et al., 2006). Inducing a feeling of financial scarcity, such as by having participants report their savings on a scale ranging from $\$ 0$ to over $\$ 50,000$ as compared with a scale from $\$ 0$ to over $\$ 500$, also reduced charitable giving (Herzenstein and Small, 2012). Another analysis found that it was not the objective adequacy of one's wealth, but rather one's emotional feelings about the adequacy of one's wealth that most strongly predicted charitable giving (Wiepking and Breeze, 2012).

The source of money may also influence its perceived importance. For example, people were less likely to donate from their payments in experiments when the money was earned by effort, rather than given as an unexpected windfall (Reinstein and Riener, 2012a). Even the form of the money can be important. People were less likely to donate from payments given to them in cash, rather than only shown on a computer screen (Reinstein and Riener, 2012a). Commitments for future contributions of money (that is, pledges) may be less tangible, and therefore easier to commit to, as compared with immediate contributions of money. Breman (2011) found that total increases in actual giving were greater when current donors were asked to commit to a future increase in giving (starting in 1 or 2 months) rather than to an immediate increase in giving.

As a matter of fundraising practice, simply reducing the cost of the gift may be counterproductive when fundraisers want to maximize resources for their charities. However, fundraisers can still limit the perceived impact of a gift on the donor's possessions by framing the cost in the most agreeable way. For example, requests framed as a share of the donor's assets rather than as a share of the donor's income can make the identical amount feel relatively smaller. Following the behavioural economics principle of loss aversion (Tversky and Kahneman, 1991), donations framed as shared from a gain in wealth (such as at the sale of a business or investment) or a gain in income (at a salary raise) may be more attractive than those framed as a loss from the donor's current wealth or income. Similarly, less tangible forms of donations such as future pledges or credit card gifts may be more attractive than immediate gifts of currency (Breman, 2011; Reinstein and Riener, 2012a). It may also be possible to combine such strategies. Just as Thaler and Benartzi (2004) found that participants increased retirement savings contributions dramatically when allowed to (1) pledge in advance to contribute (2) a share of potential future raises, so Kellner et al. (2015) found that participants increased charitable contributions when allowed to (1) pledge in advance to contribute (2) a share of a potential future winnings.

Relative to its alternatives. It is possible for a prospective donor to prefer making a gift rather than refusing to make a gift and yet still not make a gift. This will occur when the most attractive option is to avoid or postpone the giving decision. Avoidance can be particularly attractive because it may be costless, but with fewer negative social consequences than a blatant refusal. Interventions that reduce or eliminate the availability of the avoidance option may thus generate gifts from those who prefer avoidance to giving, but prefer giving to refusal.

A direct request requiring an immediate response can eliminate the avoidance option. In experiments, increasing the number of requests to give resulted in more gifts (Brown et al., 2013). In practice, alumni whose names appeared earlier in the alphabet were more likely to be called with a phone solicitation and, consequently, were more likely to make gifts to the university (Meer and Rosen, 2011).
However, when given the opportunity, a substantial share of people who would have given if asked took efforts (DellaVigna et al., 2009) or even incurred a financial penalty (Dana et al., 2006) to avoid being asked, confirming the preference of many for avoidance rather than agreement or refusal. This avoidance response might relate to some fundraisers' tendency to avoid using job titles (James, 2016) or job descriptions (Pudelek, 2014) that plainly identify them to outsiders as fundraisers.

A fundraising deadline can reduce the validity of a postponement option by publicly equating postponement with refusal. However, an immediate request typically implies the need for an immediate decision. Thus, Knowles et al. (2016) found that adding a distant deadline to an immediate request actually reduced giving, possibly by legitimizing postponement beyond an immediate decision. A postponed decision is easily forgotten and once the deadline passes, becomes irrelevant. This "delay and inattention" concept is consistent with the experimental result that when deadlines were included almost all gifting still occurred near the time of the request, and no increase in gifting occurred immediately before the stated deadline (Damgaard and Gravert, 2017: 79).

As the complexity of decisions increase, the attractiveness of decision postponement or avoidance also increases. Thus, increasing the number of options will tend to increase inaction even when all options are desirable (Botti and Iyengar, 2006). Experimentally, Carrol (2014) found that as the number of available volunteering options considered increased, so too did the tendency to postpone committing to any volunteering action.

The related practice principle emphasizes managing decision avoidance. Decision avoidance can be particularly attractive in the context of charitable giving, and thus its management is particularly important for fundraising. Clearly, this points to the importance of asking for donations. More precisely, it points to the power of simple, precise requests that require an affirmative refusal. However, managing decision avoidance is not merely a matter of asking everyone all the time. A donor may be more receptive after the development of relationships with the organization, the beneficiaries and other donors. A request may be more powerful after learning and incorporating the donor's values, preferences and life story into the specific giving opportunity. Yet, the tendency to avoid fundraising requests may preclude the interactions that facilitate these processes of discovery and relationship development. Thus, framing these initial interactions as being unrelated to fundraising requests-in order to sidestep the fundraising avoidance response-may also be an important avoidance management strategy.

\section{Conclusion and discussion}

Summary. This article proposes a comprehensive framework for charitable-giving behaviour incorporating seminal evolutionary concepts of altruism and reciprocity introduced across several decades (Hamilton, 1964; Trivers, 1971; Tooby and Cosmides, 1996; Gintis, 2000). It reviews a wide range of experimental and other empirical results within the context of the framework. These support the proposition that giving depends on the tangibility of a gift's impact on altruism (direct or code), reciprocity (transactional or friendship) and possessions relative to its alternatives. Finally, it illustrates the practical usefulness of such a framework when applied through five example principles of fundraising practice.

Applications. As a practical matter, the framework may be particularly useful in areas of fundraising less amenable to traditional experimental methods. Mass donation appeals generating many small gifts are easily amenable to scientific experiments. But here, 
practicing fundraisers can also quickly test and compare the outcomes from a wide variety of approaches even without theoretical guidance. Such is not the case with other types of fundraising, such as major donor development and charitable bequests, which typically involve long-term, or even lifetime, relationships that are not as easily manipulated for experimental testing. It is in the absence of immediate feedback and opportunities for quick experimentation where theoretical implications may become most important for fundraising practice.

Some evidence points to the usefulness of the proposed suggestions in these areas of fundraising. Although major gifts decisions are likely impossible to reproduce in an experimental setting, principles from Tooby and Cosmides (1996) evolutionary account of friendship reciprocity parallel many common practices in major gifts fundraising. This theoretical understanding may provide insight into the mechanisms underlying the effectiveness of such practices.

Bequest giving is similarly difficult to reproduce in a laboratory setting. Further, it is also different in that reciprocity motivations may become irrelevant. Before death, the gift is revocable, thus limiting the potential for significant reciprocity. After death, the donor is unable to benefit personally from reciprocity. This absence of reciprocity motivations contrasts with major lifetime gifts. Pursuing major lifetime gifts commonly requires the development of friendship reciprocity relationships and other reciprocity benefits such as naming rights or management input. Major lifetime gifts are thus highly unlikely to arrive from previously unknown benefactors. In contrast, stories abound of major bequest gifts arriving from previously unknown benefactors. This fits with the absence of reciprocity in a bequest giving context.

An absence of motivations from reciprocity in bequest giving would suggest the heightened importance of direct or code altruism. Hamilton's direct altruism calculus anticipates the reality that actual bequest transfers are largely driven by family kinship ties, typically excluding charity. Accordingly, a study of Australian donors found that the most important predictors of making a charitable bequest were believing that family was already adequately provided for or having no descendants (Baker, 2014). Similarly, a study in the United States found childlessness to be the single most powerful predictor of the likelihood of making a charitable bequest (James, 2009). Even where close family is present, charitable bequests can still fit into Hamilton's model when the potential impact on others is much greater, perhaps due to their need. A direct genetic justification is obvious when a charitable bequest supports combatting the donor's own terminal disease, as such might benefit others with similar genetic predispositions in the future.

In addition, unlike transfers to family members, a charitable bequest may provide the opportunity to express support for a code of behaviour, such as conservation of the natural environment or a religion, which, in turn, can benefit future generations. The related practice suggestion to "advance the donor hero story", emphasizes presenting the donor as one who merits lasting social approval for protecting group members or ideals (Franks et al., 2011). This matches recent experimental results in bequest giving demonstrating the power of advancing the donor hero story by sharing heroically framed life stories of similar donors (James and Routley, 2016), and using statements reflecting social approval for such gifts (Sanders and Smith, 2016).

Future research. Although corresponding with a range of empirical findings and fundraising practices, the proposed framework is far from being completely confirmed. Future research may consider more precisely testing the validity of specific elements of the proposed framework, and exploring the conditions under which different elements become relatively more or less important than others. In addition, it may be profitable to explore the extent to which certain elements are more relevant for specific sizes of gifts (ranging from small pocket change donations to major wealth transfers), specific types of gifts (cash, property, bequests) or specific charitable causes.

\section{References}

Alpizar F, Carlsson F and Johansson-Stenman O (2008) Anonymity, reciprocity, and conformity: Evidence from voluntary contributions to a national park in Costa Rica. Journal of Public Economics; 92 (5): 1047-1060.

Andreoni J (2007) Giving gifts to groups: How altruism depends on the number of recipients. Journal of Public Economics; 91 (9): 1731-1749.

Andreoni J and Petrie R (2004) Public goods experiments without confidentiality: A glimpse into fund-raising. Journal of Public Economics; 88 (7): 1605-1623.

Ariely D, Bracha A and Meier S (2009) Doing good or doing well? Image motivation and monetary incentives in behaving prosocially. The American Economic Review; 99 (1): 544-555.

Baker C (2014) Encouraging Charitable Bequests by Australians. Swinburne University of Technology: Melbourne, Australia.

Banerjee P and Chakravarty S (2014) Psychological ownership, group affiliation and other-regarding behaviour: Some evidence from dictator games. Global Economics and Management Review; 19 (1): 3-15.

Barclay P (2010) Altruism as a courtship display: Some effects of third-party generosity on audience perceptions. British Journal of Psychology; 101 (1): 123-135.

Barclay P and Willer R. (2007) Partner choice creates competitive altruism in humans. Proceedings of the Royal Society of London B: Biological Sciences; 274 (1610): 749-753.

Batson CD, Chang J, Orr R and Rowland J (2002) Empathy, attitudes, and action: Can feeling for a member of a stigmatized group motivate one to help the group? Personality and Social Psychology Bulletin; 28 (12): 1656-1666.

Ben-Ner A and Kramer A (2011) Personality and altruism in the dictator game: Relationship to giving to kin, collaborators, competitors, and neutrals. Personality and Individual Differences; 51 (3): 216-221.

Bekkers R (2010) George gives to geology Jane: The name letter effect and incidental similarity cues in fundraising. International Journal of Nonprofit and Voluntary Sector Marketing; 15 (2): 172-180.

Bekkers R and Wiepking P (2011) A literature review of empirical studies of philanthropy: Eight mechanisms that drive charitable giving. Nonprofit and Voluntary Sector Quarterly; 40 (5): 924-973.

Bohnet I and Frey BS (1999) The sound of silence in prisoner's dilemma and dictator games. Journal of Economic Behavior and Organization; 38 (1): 43-57.

Botti S and Iyengar SS (2006) The dark side of choice: When choice impairs social welfare. Journal of Public Policy \& Marketing; 25 (1): 24-38.

Brammer S and Millington A (2005) Corporate reputation and philanthropy: An empirical analysis. Journal of Business Ethics; 61 (1): 29-44.

Breman A (2011) Give more tomorrow: Two field experiments on altruism and intertemporal choice. Journal of Public Economics; 95 (11): 1349-1357.

Brown AL, Meer J and Williams JF (2013) Why Do People Volunteer? An Experimental Analysis of Preferences for Time Donations. National Bureau of Economic Research: Washington DC, (No. w19066).

Brudney V and Ferrell A (2002) Corporate charitable giving. The University of Chicago Law Review; 69 (3): 1191-1218.

Burger JM, Messian N, Patel S, del Prado A and Anderson C (2004) What a coincidence! The effects of incidental similarity on compliance. Personality and Social Psychology Bulletin; 30 (1): 35-43.

Burton-Chellew MN and Dunbar RI (2015) Hamilton's rule predicts anticipated social support in humans. Behavioral Ecology; 26 (1): 130-137.

Callen JL, Klein A and Tinkelman D (2003) Board composition, committees, and organizational efficiency: The case of nonprofits. Nonprofit and Voluntary Sector Quarterly; 32 (4): 493-520.

CASE (Council for Advancement and Support of Education). (2013) Fundraising fundamentals, http://www.case.org/Publications_and_Products/Fundraising Fundamentals_Intro/Fundraising_Fundamentals_section_7/Fundraising_Fun damentals_section_73.html, accessed 14 June 2017.

Carroll L (2014) The effect of choice set size and other choice architectures on decisions to volunteer. Dissertation Thesis. Plymouth University, UK, https:// pearl.plymouth.ac.uk/handle/10026.1/3003.

Castro MF (2008) Where are you from? Cultural differences in public good experiments. The Journal of Socio-Economics; 37 (6): 2319-2329.

Charness G and Gneezy U (2008) What's in a name? Anonymity and social distance in dictator and ultimatum games. Journal of Economic Behavior and Organization; 68 (1): 29-35.

Converse BA, Risen JL and Carter TJ (2012) Investing in karma when wanting promotes helping. Psychological Science; 23 (8): 923-930. 
Coutts and Co. (2015) Coutts Million Pound Donors report, http://philanthropy. coutts.com/en/reports/2015/united-states/findings.html and http://philan thropy.coutts.com/en/reports/2015/united-kingdom/findings.html.

Croson R, Handy F and Shang J (2009) Keeping up with the joneses: The relationship of perceived descriptive social norms, social information, and charitable giving. Nonprofit Management and Leadership; 19 (4): 467-489.

Crumpler $\mathrm{H}$ and Grossman PJ (2008) An experimental test of warm glow giving. Journal of Public Economics; 92 (5): 1011-1021.

Cryder CE, Loewenstein G and Seltman H (2013) Goal gradient in helping behavior. Journal of Experimental Social Psychology; 49 (6): 1078-1083.

Damgaard MT and Gravert C (2017) Now or never! The effect of deadlines on charitable giving: Evidence from two natural field experiments. Journal of Behavioral and Experimental Economics; 66 (1): 78-87.

Dale DJ (2004) Charitable lottery structure and fund raising: Theory and evidence. Experimental Economics; 7 (3): 217-234.

Dana J, Cain DM and Dawes RM (2006) What you don't know won't hurt me: Costly (but quiet) exit in dictator games. Organizational Behavior and Human Decision Processes; 100 (2): 193-201.

Darlington RB and Macker CE (1966) Displacement of guilt-produced altruistic behavior. Journal of Personality and Social Psychology; 4 (4): 442.

DellaVigna S, List JA and Malmendier U (2009) Testing for Altruism and Social Pressure in Charitable Giving; Washington DCNational Bureau of Economic Research, (No. w15629)

Dickert S, Kleber J, Västfäll D and Slovic P (2016) Mental imagery, impact, and affect: A mediation model for charitable giving. PLoS ONE; 11 (2): e0148274.

Dickert S and Slovic P (2009) Attentional mechanisms in the generation of sympathy. Judgment and Decision Making; 4 (4): 297-306.

Eckel CC and Grossman PJ (2008) Subsidizing charitable contributions: A natural field experiment comparing matching and rebate subsidies. Experimental Economics; 11 (3): 234-252.

Eckel CC, Herberich DH and Meer J (2017) A field experiment on directed giving at a public university. Journal of Behavioral and Experimental Economics; 66 (1): 66-71.

Eller MB (2001) Charitable bequests: Evidence from federal estate tax returns. IRS Statistics of Income Bulletin; (Publication 1136, Revised 5/01): 174-190.

Epp DJ and Wicinas JD (2001) Voluntary provision of public goods: An experimental economics study, http://wicinas.homestead.com/NAREA_Paper.pdf, accessed 14 June 2017.

Erlandsson A, Björklund F and Bäckström M (2014) Perceived utility (not sympathy) mediates the proportion dominance effect in helping decisions. Journal of Behavioral Decision Making; 27 (1): 37-47.

Falk A (2003) Charitable giving as a gift exchange. Institute for Empirical Research in Economics, University of Zurich, http://www.econ.uzh.ch/static/wp_iew/ iewwp168.pdf.

Fehr E and Gächter S (2002) Altruistic punishment in humans. Nature; 415 (6868): $137-140$.

Fehr E, Schmidt KM (2006) The economics of fairness, reciprocity and altruismexperimental evidence and new theories. In: Kolm SC, SC and Ythier JM (eds). Handbook of the Economics of Giving, Altruism and Reciprocity. Elsevier: New York, pp 615-691.

Fehrler S and Przepiorka W (2013) Charitable giving as a signal of trustworthiness: Disentangling the signaling benefits of altruistic acts. Evolution and Human Behavior; 34 (2): 139-145.

Franco ZE, Blau K and Zimbardo PG (2011) Heroism: A conceptual analysis and differentiation between heroic action and altruism. Review of General Psychology; 15 (2): 99.

Fraser ON and Bugnyar T (2010) The quality of social relationships in ravens. Animal Behavior; 79 (4): 927-933.

Fraser ON, Schino G and Aureli F (2008) Components of relationship quality in chimpanzees. Ethology; 114 (9): 834-843.

Gintis H (2000) Strong reciprocity and human sociality. Journal of Theoretical Biology; 206 (2): 169-179.

Gintis H (2003) The Hitchhiker's guide to altruism: Gene-culture coevolution, and the internalization of norms. Journal of Theoretical Biology; 220 (4): $407-418$.

Glazer A and Konrad KA (1996) A signaling explanation for charity. The American Economic Review; 86 (4): 1019-1028.

Gneezy U, Keenan EA and Gneezy A (2014) Avoiding overhead aversion in charity. Science; 346 (6209): 632-635.

Griskevicius V, Tybur JM, Sundie JM, Cialdini RB, Miller GF and Kenrick DT (2007) Blatant benevolence and conspicuous consumption: When romantic motives elicit strategic costly signals. Journal of Personality and Social Psychology; 93 (1): 85.

Guéguen N and Lamy L (2011) The effect of the word 'love' on compliance to a request for humanitarian aid: An evaluation in a field setting. Social Influence; 6 (4): 249-258.

Hamilton WD (1964) The genetical evolution of social behaviour. II. Journal of Theoretical Biology; 7 (1): 17-52.
Hansmann H (1987) Economic theories of nonprofit organization. In: Powell WW (ed). The Nonprofit Sector: A Research Handbook. Yale University Press: New Haven, CT, pp 27-42.

Hardy CL and Van Vugt M (2006) Nice guys finish first: The competitive altruism hypothesis. Personality and Social Psychology Bulletin; 32 (10): 1402-1413.

Helms S, Scott B and Thornton J (2013) New experimental evidence on charitable gift restrictions and donor behaviour. Applied Economics Letters; 20 (17): 1521-1526.

Herzenstein M and Small D (2012) Donating in recessionary times: Resource scarcity, social distance, and charitable giving. NA-Advances in Consumer Research; 40 (1): 13-17.

Hidano $\mathrm{N}$ and Ogiso $\mathrm{T}$ (2012) Why do people donate more than a fair share? An experimental investigation of a complete crowding-out situation with a social frame. Discussion Paper No. 2012-4 Tokyo Institute of Technology, Japan.

Hopkins BR (2008) Private Foundation Law Made Easy. John Wiley and Sons: Hoboken, NJ.

Hopkins N, Reicher S, Harrison K, Cassidy C, Bull R and Levine M (2007) Helping to improve the group stereotype: On the strategic dimension of prosocial behavior. Personality and Social Psychology Bulletin; 33 (6): 776-788.

Huck S and Rasul I (2010) Transactions costs in charitable giving: Evidence from two field experiments. The BE Journal of Economic Analysis and Policy; 10 (1): $1-31$.

Iannaccone LR (1998) Introduction to the economics of religion. Journal of Economic Literature; 36 (3): 1465-1495.

Iredale W, Van Vugt M and Dunbar R (2008) Showing off in humans: Male generosity as a mating signal. Evolutionary Psychology; 6 (3): 386-392.

James RN (2009) Health, wealth, and charitable estate planning: A longitudinal examination of testamentary charitable giving plans. Nonprofit and Voluntary Sector Quarterly; 38 (6): 1026-1043.

James RN (2016) Testing the effectiveness of fundraiser job titles in charitable bequest and complex gift planning. Nonprofit Management and Leadership; 27 (2): 165-179.

James RN and Routley C (2016) We the living: The effects of living and deceased donor stories on charitable bequest giving intentions. International Journal of Nonprofit and Voluntary Sector Marketing; 21 (2): 109-117.

Jenni K and Loewenstein G (1997) Explaining the identifiable victim effect. Journal of Risk and Uncertainty; 14 (3): 235-257.

Karylowski J (1976) Self-esteem, similarity, liking and helping. Personality and Social Psychology Bulletin; 2 (71): 71-74.

Kelly S and Dunbar RIM (2001) Who dares, wins: Heroism versus altruism in women's mate choice. Human Nature; 12 (2): 89-105.

Kellner C, Reinstein D and Riener G (2015) Stochastic income and conditional generosity. Available at SSRN: http://dx.doi.org/10.2139/ssrn.2691027.

Kim DG (2015) The coin strategy and charitable giving. California Institute of Technology-Economics. Available at SSRN: https://ssrn.com/abstract $=$ 2745071.

Klinowski D, Argo N and Krishnamurti T (2015) The completion effect in charitable crowdfunding, https://davs-econ.github.io/KlinowskiArgoKrishna murtiCrowdfunding.pdf, accessed 14 June 2017.

Knowles S, Servátka M and Sullivan T (2016) Deadlines, procrastination, and inattention in charitable tasks: A field experiment. Available at SSRN: http://dx. doi.org/10.2139/ssrn.2576625.

Kogut $\mathrm{T}$ and Ritov I (2005) The singularity effect of identified victims in separate and joint evaluations. Organizational Behavior and Human Decision Processes; 97 (2): 106-116.

Krupka EL and Croson RT (2016) The differential impact of social norms cues on charitable contributions. Journal of Economic Behavior and Organization; 128 (1): 149-158.

Lev B, Petrovits C and Radhakrishnan S (2010) Is doing good good for you? How corporate charitable contributions enhance revenue growth. Strategic Management Journal; 31 (2): 182-200.

Lindahl WE (2009) Principles of Fundraising: Theory and Practice. Jones and Bartlett Learning: Sudbury, MA.

Malhotra D (2010) 'Sunday effect' on pro-social behavior. Judgment and Decision Making; 5 (2): 138-143.

Martin R and Randal J (2008) How is donation behaviour affected by the donations of others? Journal of Economic Behavior \& Organization; 67 (1): 228-238.

Massen JJM (2010) 'Friendship' in Macaques. Economics and emotions. PhD Thesis, Utrecht University, Utrecht, the Netherlands.

McKay R, Efferson C, Whitehouse H and Fehr E (2011) Wrath of god: Religious primes and punishment. Proceedings of the Royal Society of London B: Biological Sciences; 278 (1713): 1858-1863.

Meer J and Rosen HS (2009) Altruism and the child cycle of alumni donations. American Economic Journal: Economic Policy; 1 (1): 258-286.

Meer J and Rosen HS (2011) The ABCs of charitable solicitation. Journal of Public Economics; 95 (5): 363-371 
Miller G (2011) The Mating Mind: How Sexual Choice Shaped the Evolution of Human Nature. Knopf Doubleday Publishing Group: New York.

Naeem S and Zaman A (2009) Charity and gift exchange in Pakistan. Available at SSRN: https://ssrn.com/abstract $=1443568$

Nolan H (2016) Stop giving money to rich colleges. Gawker. 27 January, http:// gawker.com/stop-giving-money-to-rich-colleges-1755420799.

Newman GE and Shen YJ (2012) The counterintuitive effects of thank-you gifts on charitable giving. Journal of Economic Psychology; 33 (5): 973-983.

Ohtsubo Y and Watanabe E (2013) Unintentional unfair behavior promotes charitable donation. Letters on Evolutionary Behavioral Science; 4 (1): 1-4.

Olivola CY and Shafir E (2013) The martyrdom effect: When pain and effort increase prosocial contributions. Journal of Behavioral Decision Making; 26 (1): 91-105.

Petropoulou A (1987) The sacrifice of eumaeus reconsidered. Greek, Roman and Byzantine Studies; 28 (2): 135.

Pudelek J (2014) Eleven characteristics of successful fundraisers revealed at IoF National Convention. 10 July, http://www.civilsociety.co.uk/fundraising/news/ content/17819/eleven_characteristics_of_successful_fundraisers_revealed_at_ iof_national_convention.

Reinstein D and Riener G (2012a) Decomposing desert and tangibility effects in a charitable giving experiment. Experimental Economics; 15 (1): 229-240.

Reinstein D and Riener G (2012b) Reputation and influence in charitable giving: An experiment. Theory and Decision; 72 (2): 221-243.

Rushton JP (1989) Genetic similarity, human altruism, and group selection. Behavioral and Brain Sciences; 12 (3): 503-559.

Sachdeva S, Iliev R and Medin DL (2009) Sinning saints and saintly sinners the paradox of moral self-regulation. Psychological Science; 20 (4): 523-528.

Sanders M and Smith S (2016) Can simple prompts increase bequest giving? Field evidence from a legal call centre. Journal of Economic Behavior and Organization; 125 (1): 179-191.

Schank RC, Abelson RP (1995) Knowledge and memory: The real story. In: Wyer Jr. RS (ed). Knowledge and Memory: The Real Story. Lawrence Erlbaum Associates: Hillsdale, NJ, pp 1-85.

Segal NL and Hershberger SL (1999) Cooperation and competition between twins: Findings from a prisoner's dilemma game. Evolution and Human Behavior; 20 (1): $29-51$.

Shariff AF and Norenzayan A (2007) God is watching you priming god concepts increases prosocial behavior in an anonymous economic game. Psychological Science; 18 (9): 803-809.

Slovic P (2007) 'If I look at the mass I will never act': Psychic numbing and genocide. Judgment and Decision Making; 2 (2): 79-95.

Small DA, Loewenstein G and Slovic P (2007) Sympathy and callousness: The impact of deliberative thought on donations to identifiable and statistical victims. Organizational Behavior and Human Decision Processes; 102 (2): 143-153.

Smith RW, Faro D and Burson KA (2013) More for the many: The influence of entitativity on charitable giving. Journal of Consumer Research; 39 (5): 961-976.

Strahilevitz M and Myers JG (1998) Donations to charity as purchase incentives: How well they work may depend on what you are trying to sell. Journal of Consumer Research; 24 (4): 434-446.
Strittmatter EJ (1925) Prayer in the Iliad and the Odyssey. The Classical Weekly; 18 (11): 83-87.

Tessman I (1995) Human altruism as a courtship display. Oikos; 74 (1): 157-158.

Thaler RH and Benartzi S (2004) Save more tomorrow ${ }^{\mathrm{m}}$ : Using behavioral economics to increase employee saving. Journal of Political Economy; 112 (S1): S164-S187.

Tooby J and Cosmides L (1996) Friendship and the banker's paradox: Other pathways to the evolution of adaptations for altruism. Proceedings of the British Academy; 88 (1): 119-143.

Trivers RL (1971) The evolution of reciprocal altruism. Quarterly Review of Biology; 46 (1): 35-57.

Tversky A and Kahneman D (1991) Loss aversion in riskless choice: A reference-dependent model. The Quarterly Journal of Economics; 106 (4): 1039-1061.

Vohs KD, Mead NL and Goode MR (2006) The psychological consequences of money. Science; 314 (5802): 1154-1156.

Wiepking P and Breeze B (2012) Feeling poor, acting stingy: The effect of money perceptions on charitable giving. International Journal of Nonprofit and Voluntary Sector Marketing; 17 (1): 13-24.

Zak PJ, Stanton AA and Ahmadi S (2007) Oxytocin increases generosity in humans. PLoS ONE; 2 (11): e1128.

\section{Data availability}

Data sharing is not applicable to this article, as no data sets were generated or analysed during the current study.

\section{Additional information}

Competing interests: The author declares that there are no competing interests.

Reprints and permission information is available at http://www.palgrave-journals.com/ pal/authors/rights_and_permissions.html

How to cite this article: James III R (2017) Natural philanthropy: a new evolutionary framework explaining diverse experimental results and informing fundraising practice. Palgrave Communications. 3:17050 doi: 10.1057/palcomms.2017.50.

Publisher's note: Springer Nature remains neutral with regard to jurisdictional claims in published maps and institutional affiliations.

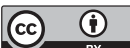

This work is licensed under a Creative Commons Attribution 4.0 International License. The images or other third party material in this article are included in the article's Creative Commons license, unless indicated otherwise in the credit line; if the material is not included under the Creative Commons license, users will need to obtain permission from the license holder to reproduce the material. To view a copy of this license, visit http://creativecommons.org/licenses/by/4.0/

C) The Author(s) 2017 